\title{
Journal of Science and Engineering
}

Full Paper

\section{PENYEBARAN ENDAPAN NIKEL LATERIT PULAU OBI KABUPATEN HALMAHERA SELATAN PROVINSI MALUKU UTARA}

\author{
Arbi Hayaa*, Wawan Ak. Conoras ${ }^{\mathrm{a}}$, Firman ${ }^{\mathrm{a}}$ \\ aUniversitas Khairun, Ternate, Indonesia
}

Article history

Received

5 Maret 2019

Received in revised form

17 April 2019

Accepted

25 April 2019

*Corresponding author arbihaya@gmail.com

\section{Graphical abstract}

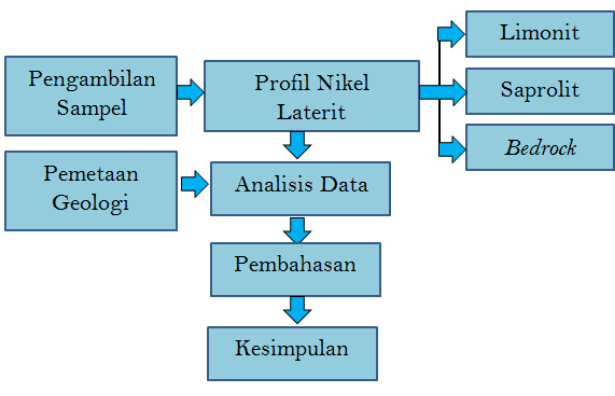

\begin{abstract}
Nickel laterite is a residual product of chemical weathering in ultramafic rocks. Weathering on peridotite causes elements with low mobility to immobile such as $\mathrm{Ni}, \mathrm{Fe}$ and $\mathrm{Co}$ to experience residual and secondary enrichment. Obi Island is one of the areas considered to be a prospect of laterite nickel deposits, especially in the northern part of Obi Island. The metal content of $\mathrm{Ni}$ (nickel), $\mathrm{Fe}$ (iron), and Co (cobalt), in this area is the result of weathering from dunits. This study conducted a more specific study of the spread of laterite nickel deposits, especially in Obi Island, South Halmahera Regency, North Maluku Province. The lithology of the study area is composed by conglomerates, diorites and dunits. The profile of laterite nickel deposits in the study area consisted of limonite, saprolite and bedrock zones. Limonite zone thickness varies from 1-5 meters. The thickness of the saprolite zone reaches 16 meters. Based on the research it can be concluded that the geochemical profile in the study area leads to abnormal distribution of existing elements, both $\mathrm{Ni}, \mathrm{Co}, \mathrm{Fe}, \mathrm{SiO} 2, \mathrm{CaO}$ and $\mathrm{MgO}$ elements. In addition, the thickness and depth of lateritic nickel deposits can vary. Therefore it is necessary to do more in-depth research on the spread of laterite nickel deposits because each location has different characteristics.
\end{abstract}

Keywords: Nickel laterite, Obi Island, saprolite, limonite

\begin{abstract}
Abstrak
Nikel laterit adalah produk residual pelapukan kimia pada batuan ultrabasa. Pelapukan pada peridotit menyebabkan unsur-unsur dengan mobilitas rendah sampai immobile seperti Ni, Fe dan Co mengalami pengayaan secara residual dan sekunder. Pulau Obi merupakan salah satu daerah yang dianggap prospek terhadap endapan nikel laterit terutama di Pulau Obi bagian Utara. Kandungan logam Ni (nikel), Fe (besi), dan Co (kobal), di daerah ini merupakan hasil pelapukan dari dunit. Penelitian ini melakukan pengkajian lebih spesifik mengenai penyebaran endapan nikel laterit khususnya di Pulau Obi, Kabupaten Halmahera Selatan, Propinsi Maluku Utara. Litologi daerah penelitian disusun oleh konglomerat, diorit dan dunit. Profil endapan nikel laterit daerah penelitian terdiri atas zona limonit, saprolit dan bedrock. Ketebalan zona limonit bervariasi dari $1-5$ meter. Ketebalan zona saprolit mencapai 16 meter. Berdasarkan penelitian dapat disimpulkan bahwa profil geokimia di daerah penelitian menujukan terjadinya ketidak normalan distribusi unsur-unsur yang ada, baik unsur $\mathrm{Ni}, \mathrm{Co}, \mathrm{Fe}, \mathrm{SiO}_{2}, \mathrm{CaO}$ dan $\mathrm{MgO}$. Selain itu, ketebalan dan kedalaman endapan nikel laterit dapat bervariasi. Oleh karena itu perlu dilakukan penelitian yang lebih mendalam lagi mengenai penyebaran endapan nikel laterit karena setiap lokasi memiliki karakteristik yang berbeda.
\end{abstract}

Kata kunci: Nikel laterit, Pulau Obi, saprolit, limonit 


\subsection{PENDAHULUAN}

Saat ini tidak satu negara pun mempunyai cadangan yang cukup untuk memenuhi kebutuhan industrinya. Dengan demikian dari tahun ke tahun banyak pihak yang mencari (eksplorasi) sumber endapan yang mengandung bijih yang sifatnya ekonomis untuk mengimbangi kebutuhan industrinya. Salah satu endapan bijih yang mempunyai target eksplorasi adalah endapan nikel laterit.

Nikel laterit adalah produk residual pelapukan kimia pada batuan ultrabasa. Proses ini berlangsung selama jutaan tahun dimulai ketika batuan ultrabasa tersingkap di permukaan bumi. Pelapukan pada peridotit menyebabkan unsur-unsur dengan mobilitas rendah sampai immobile seperti Ni (nikel), Fe (besi) dan Co (kobal) mengalami pengayaan secara residual dan sekunder [1].

Secara ekonomi, endapan nikel laterit mempunyai daya tarik yang tinggi. Endapan nikel laterit diperkirakan akan menjadi sumber utama dari produk nikel di masa mendatang [2]. Keunggulan atau daya tarik endapan nikel laterit karena mengandung $\mathrm{Ni}$ (nikel), Fe (besi) dan Co (kobal) dalam jumlah yang ekonomis untuk diekstraksi [3]. Pulau Obi merupakan salah satu daerah yang dianggap prospek terhadap endapan nikel laterit terutama di Pulau Obi bagian Utara. Kandungan logam Ni (nikel), Fe (besi), dan Co (kobal), di daerah ini merupakan hasil pelapukan dari dunit [4].

Prospek dan potensi sumberdaya mineral tersebut, sampai sekarang belum terungkap secara detail. Dengan demikian penulis tertarik melakukan penelitian untuk mengkaji dan mengungkap lebih spesifik mengenai penyebaran endapan nikel laterit khususnya di Pulau Obi, Kabupaten Halmahera Selatan, Propinsi Maluku Utara.

\subsection{METODOLOGI}

Pengujian ini dilakukan di Laboratorium Geologi Program Studi Teknik Pertambangan Fakultas Teknik Universitas Khairun. Lokasi penelitian yang dilakukan tepatnya di Daerah Loji yang secara administratif terletak di Kecamatan Obi Utara, Kabupaten Halmahera Selatan, Propinsi Maluku Uatara. Secara geografis

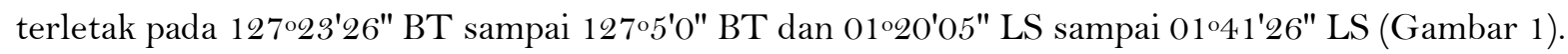

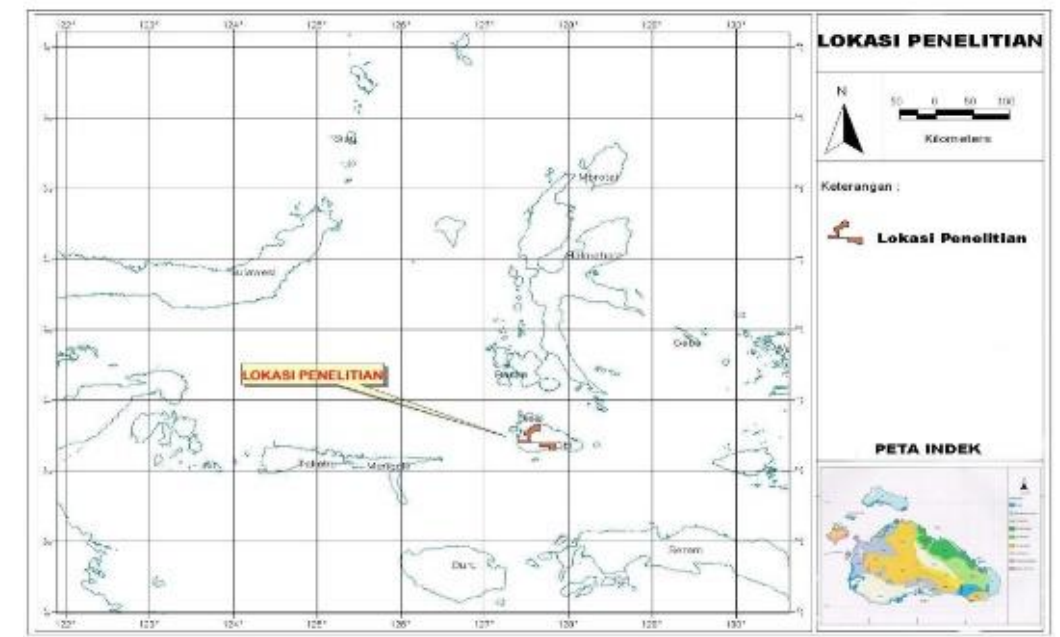

Gambar 1. Peta Administrasi Daerah Penelitian

Kebutuhan Penelitian meliputi lup pembesar 10 kali, kompas geologi, perlengkapan safety (helm dan sepatu lapangan, kantong sampel, peta geologi, komputer dan GPS (Global Positioning System). Prosedur Penelitian meliputi

2.1. Studi Pendahuluan (desk study)

Studi pendahuluan mencakup studi literatur, geologi permukaan baik regional maupun lokal diantaranya geomorfologi, litologi, stratigrafi, dan struktur geologi khusus di daerah penelitian. 


\subsection{Pekerjaan Lapangan}

Pekerjaan lapangan untuk mengumpulkan data primer maupun mencakup pemetaan geologi detail dan pengambilan conto batuan baik dipermukaan maupun di bawah permukaan (pemboran inti) dengan prosedur sebagai berikut:

a) Pemetaan Topografi

Program ini untuk memetakan bentukan morfologi di daerah penelitian dengan skala detail ( $1: 1.000)$, pembuatan grid line titik-titik rencana pengeboran inti maupun bekas titik-titik obyeklainnya terutama pengeboran inti. Daerah yang akan dipetakan biasanya daerah yang memiliki potensi nikel laterit.

b) Pemetaan Geologi

Pemetaan geologi ini merupakan tahapan paling awal dari kegiatan eksplorasi. Target pemetaan geologi ini adalah memetakan kondisi geologi di daerah penelitian terutama jenis dan penyebaran batuannya. Selain itu dapat mengetahui luas penyebaran potensi nikel laterit.

c) Pengambilan sampel

Pengambilan sampel bertujuan untuk mendapatkan sampel yang representatif di permukaan maupun di bawah permukaan dengan mengunakan sistim pemboran inti di daerah Pulau Obi Kab. Halmaherah Selatan, Provinsi Maluku Utara. Kegiatan pemboran inti dengan tujuan mendapatkan conto endapan nikel secara vertikal yang berada di bawah permukaan tanah. Program ini merupakan tindak lanjut dari program sebelumnya yaitu pembuatan sumur uji dengan target kedalaman sampai batuan dasar sepanjang \pm 22 meter. Hasil dari program ini adalah mengetahui variasi, ketebalan masing-masing zona laterit secara lengkap, sehingga membantu dalam estimasi cadangan nikel laterit.

\subsection{HASIL DAN PEMBAHASAN}

\subsection{Geologi Daerah Penelitian}

\section{a) Morfologi}

Morfologi di daerah penelitian terdapat satuan perbukitan bergelombang lemah dan satuan perbukitan bergelombang terjal. Satuan perbukitan bergelombang lemah menempati sebelah utara memanjang dari timur ke barat dengan ketinggian 50 - 250 meter di permukaan laut dan kemiringan lereng (5-20) , punggungan lebar dan semakin menyempit ke arah selatan dan barat. Satuan perbukitan bergelombang terjal menempati sebelah selatan dan sebagian bagian barat daerah penelitian. Satuan perbukitan umumnya membentuk morfologi kerucut dengan punggungan sempit dengan ketinggian 250 - 310 meter diatas permukaan laut dan kemiringan lereng (30-50) ${ }^{\circ}$. Pembentukan satuan ini dipengaruhi oleh struktur kekar dan sesar yang dapat diamati dari adanya gawir sesar yang memisahkan antara bukit. yang di sebelah barat dengan yang di sebalah timur dan adanya batuan terbreksikan serta tererosi lanjut.Sesar ini memanjang dariutara selatan. Daerah dengan tingkat kelerengan landai sampai sedang merupakan tempat pengkayaan nikel, sedangkan pada daerah dengan tingkat kelerengan curam, terjadi erosi mekanik dan akan membawa unsur-unsur nikel sebelum unsur-unsur tersebut membentuk endapan nikel laterit.

\section{b) Struktur Geologi}

Struktur geologi yang berkembang adalah struktur kekar dan sesar. Struktur kekar pada batuan peridotit terisi oleh mineral serpentin. umumnya berkembang pada batuan dunit dan kadang terisi oleh mineral silika, serpentin dan garnierit. Struktur sesar dapat diamati dari adanya gawir sesar yang memisahkan antara bukit yang di sebelah barat dengan yang di sebalah timur dan adanya batuan terbreksikan serta tergerus. Sesar ini memanjang dari utara selatan [5].

\subsection{Penyebaran endapan nikel laterit daearah penelitian}

Berdasarkan litologi di sekitar lokasi penelitian tidak dijumpai adanya singkapan, tetapi berdasarkan hasil penelitian terdahulu yang dilakukan oleh Tim geologis PT. Antam Tbk [6], litologi daerah penelitian disusun oleh konglomerat, diorit dan dunit. 


\section{a) Konglomerat}

Batuan konglomerat terletak disebelah barat dan menyebar ke selatan sampai ke arah Akelamo. Kenampakan fisik memperlihatkan warna abu-abu sampai kemerahan (lapuk), masif, berkomposisi klastika kasar berukuran pasir hingga kerakal, dengan fragmen dan matriks tersusun oleh diorit, rijang dan ultrabasa dengan semen non karbonat berupa silika. Pada bagian selatan tanah pelapukan batuan ini memperlihatkan warna merah seperti laterit yang berasal dari batuan ultrabasa.

\section{b) Diorit}

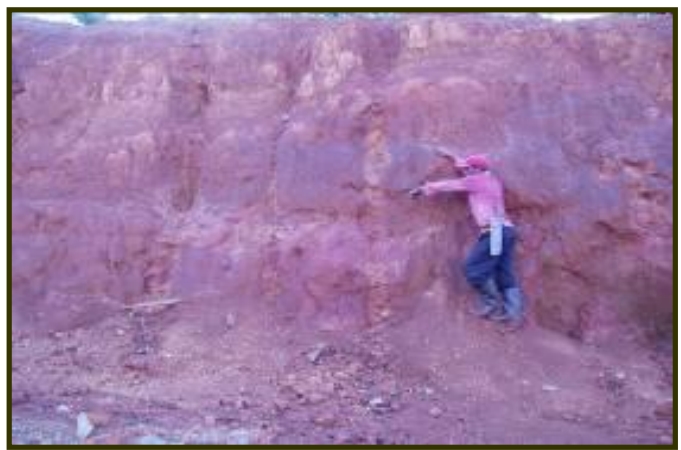

Gambar 2. Singkapan konglomerat, menempati bagian barat Loji

Batuan diorit tersebar disebelah timur dan menyebar ke arah selatan daerah penelitian. Kenampakan fisik memperlihatkan warna abu-abu, tekstur kasar, didominasi mineral feldspar dan kuarsa. Tanah hasil pelapukan batuan ini berwarna merah sampai abu-abu kecoklatan kehijauan, lunak, liat, berbutir halus, juga dijumpai uraturat lempung, dengan komposisi kuarsa, ortoklas, hornblende dan biotit.

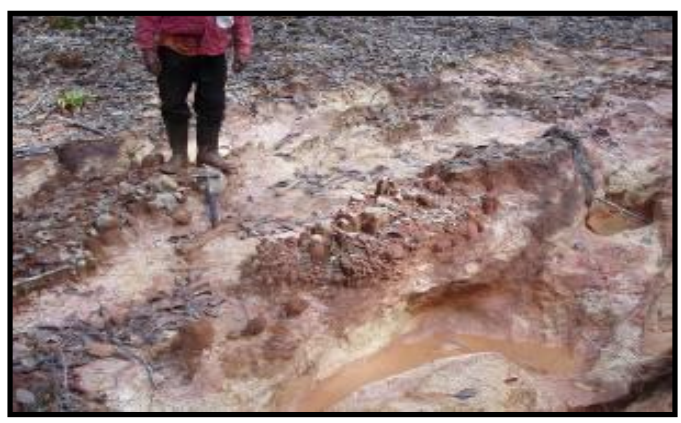

Gambar 3. Singkapan diorit, menempati bagian timur Loji

\section{c) Dunit}

Dunit tersebar luas menempati kurang lebih $80 \%$ dari luas daerah penelitian dan terletak pada bagian tengah, menyebar ke utara dan selatan. Kenampakan fisik memperlihatkan warna hijau, tekstur halus hingga kasar, mengalami pelapukan dan serpentinisasi dengan derajat bervariasi, terkekarkan dan terisi oleh mineral silika, serpentin dan garnierit.

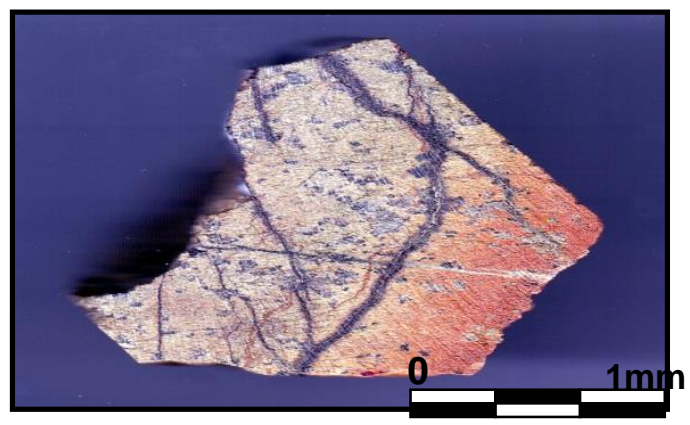

Gambar 4. Dunit salah satu batuan dasar didaerah penelitian. titik bor Cl. 00009 


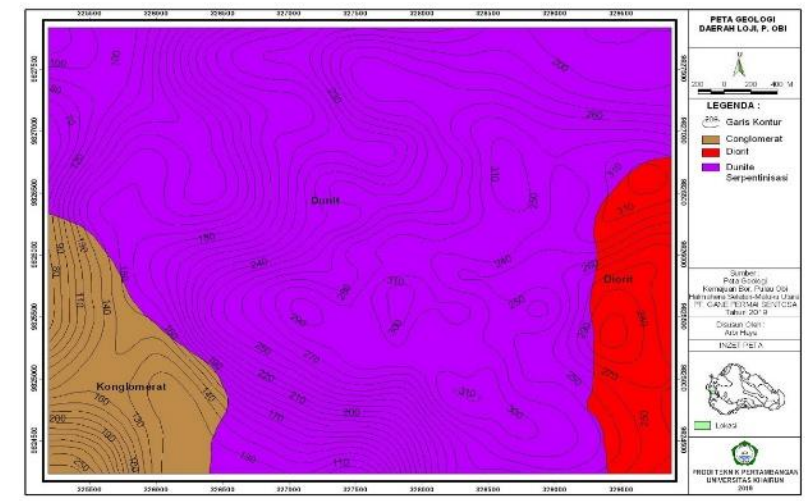

Gambar 5. Peta geologi daerah penelitian [7]

\subsection{Profil Endapan Nikel Laterit Daerah Penelitian}

Profil endapan nikel laterit menjelaskan tentang pembentukan zona atau perlapisan serta penyebaran endapan bawah permukaan, berdasarkan profil endapan niklel laterit daerah penelitian terdiri atas zona limonit, saprolit dan bedrock. Dari data titik bor, ketebalan dan pola penyebaran endapan bervariasi, baik zona limonit, saprolit dan bedrock. Secara keseluruhan ketebalan zona mencapai 22 meter. Untuk lebih jelas gambaran Profil endapan nikel laterit menjelaskan tentang pembentukan zona atau perlapisan serta penyebaran endapan bawah permukaan. Ada 4 penempang geologi yang dapat terwakilkan untuk mengetahui kondisi penyebaran batuan dibawah permukaan sebagai berikut:

a) Penampang $\mathrm{A}-\mathrm{B}$

Pada penampang 1 terdiri dari 3 titik bor yang dijadikan sebagai pembuatan penampang profil endapan, kedalaman titik bor mecapai $20 \mathrm{~m}$, terdapat 3 batas zona berdasarkan lithologi, dengan ketebalan tiapa zona bervariasi, zona limonit rata $0-3 \mathrm{~m}$, zona saprolit $3-20 \mathrm{~m}$ dan zona bedrock $18-20 \mathrm{~m}$.

b) Penambang C - D

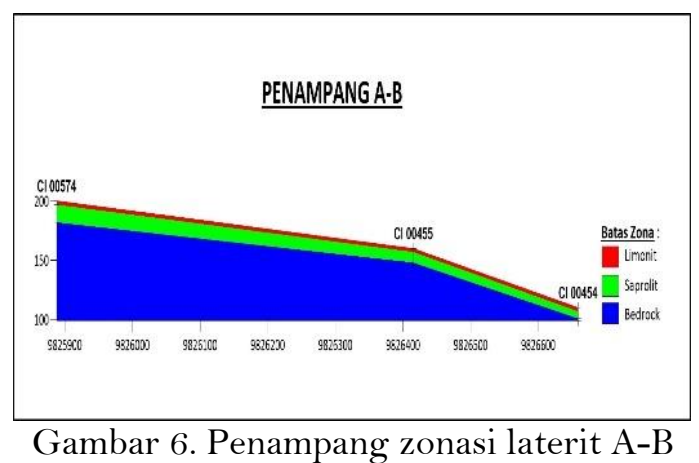

Pada penampang 2 terdiri dari 3 titik bor yang dijadikan sebagai pembuatan penampang profil endapan, kedalaman titik bor mecapai $20 \mathrm{~m}$, terdapat 3 batas zona berdasarkan lithologi, dengan ketebalan tiapa zona bervariasi, zona limonit rata $\mathrm{O}-3 \mathrm{~m}$, zona saprolit $3-20 \mathrm{~m}$ dan zona bedrock $18-20 \mathrm{~m}$.

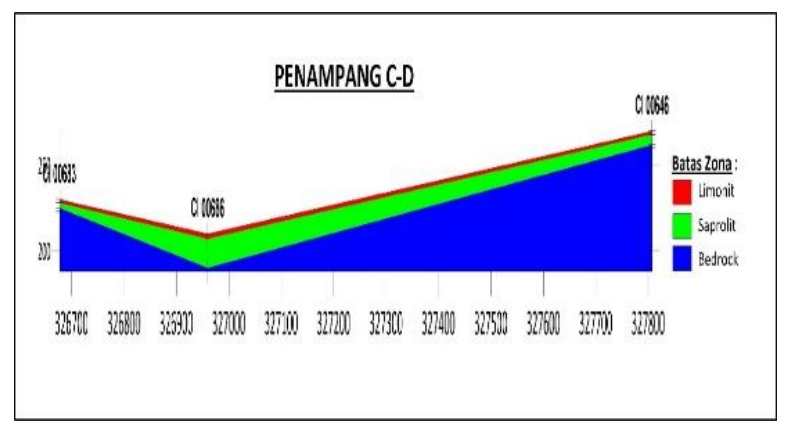

Gambar 7. Penampang Zonasi Laterit C-D 
c) Penampang E - F

Pada penampang 3 terdiri dari 3 titik bor yang dijadikan sebagai pembuatan penampang profil endapan, kedalaman titik bor mecapai $20 \mathrm{~m}$, terdapat 3 batas zona berdasarkan lithologi, dengan ketebalan tiapa zona bervariasi, zona limonit rata $0-3 \mathrm{~m}$, zona saprolit $3-20 \mathrm{~m}$ dan zona bedrock $18-20 \mathrm{~m}$.

d) Penampang $\mathrm{G}-\mathrm{H}$

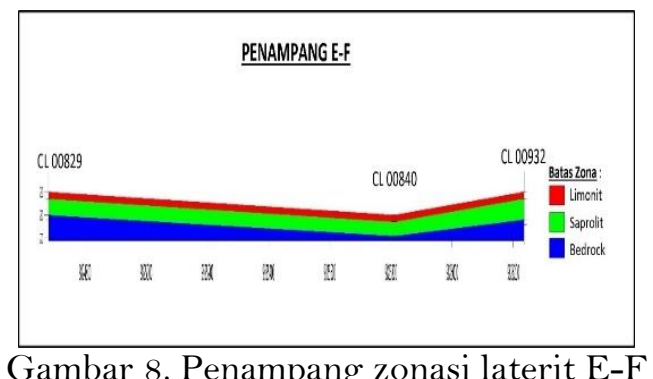

Pada penampang 1 terdiri dari 3 titik bor yang dijadikan sebagai pembuatan penampang profil endapan, kedalaman titik bor mecapai $20 \mathrm{~m}$, terdapat 3 batas zona berdasarkan lithologi, dengan ketebalan tiapa zona bervariasi, zona limonit rata $0-3 \mathrm{~m}$, zona saprolit $3-20 \mathrm{~m}$ dan zona bedrock $18-20 \mathrm{~m}$.

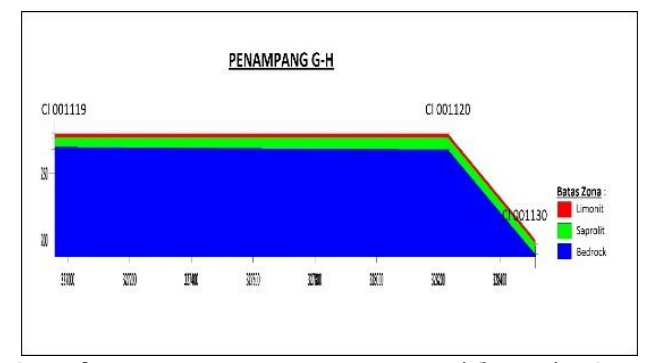

Gambar 9. Penampang zonasi laterit G-H

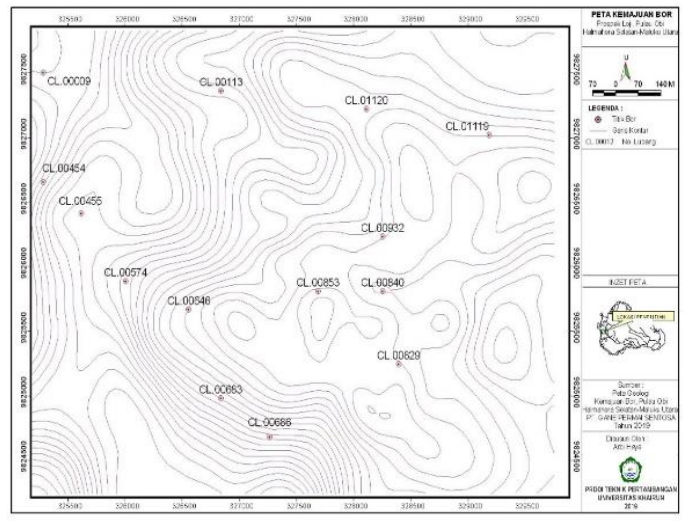

Gambar 10. Peta Kemajuan titik bor daerah penelitian

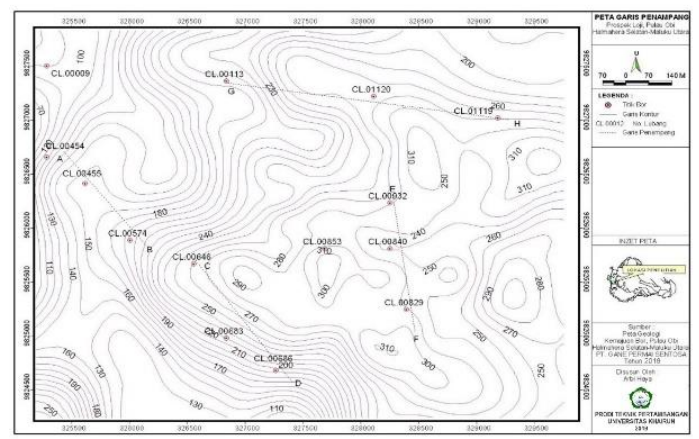

Gambar 11. Peta penampang titik bor daerah penelitian

(2019) 25-33 | http://ejournal.unkhair.ac.id/index.php/josae | ISSN 2621-3435 | 


\subsection{Penyebaran endapan nikel laterit berdasarkan zona}

Endapan nikel laterit di daerah penelitian dapat dijabarkan menjadi beberapa zona diantaranya zona limonit, saprolit dan bedrock. Berdasarkan hasil analisa petrografi, XRD, dan analisis kimia pada tiap zona endapan nikel laterit adalah sebagai berikut:

\section{a) Zona Limonit}

Pada bagian atas ini dijumpai kombinasi antara humus dan limonit dengan warna coklat kemerahan, coklat kekuningan, kekerasan batuan lapuk sampai sedang, ukuran butir (Ø) halus sampai sedang. Secara kimiawi zona limonit umumnya ditentukan atas kelimpahan unsur-unsur yang tidak mudah larut (residual) seperti $\mathrm{Fe}, \mathrm{Al}, \mathrm{Cr}$, $\mathrm{Ti}, \mathrm{Mn}$ dan Co [8], akan tetapi dalam hal ini unsur yang paling sering dipakai adalah Fe karena biasanya berasosiasi dengan mineral utama yang dijumpai pada zona limonit seperti gotit, mangan oksida (asbolit), oksida besi limonit dan hematit. Pada zona limonit unsur $\mathrm{Mg}$ dijumpai dalam jumlah kecil karena $\mathrm{Mg}$ biasanya berasosiasi dengan mineral olivin [9], piroksen dan serpentin yang tidak dijumpai di zona ini. Unsur Ni biasanya dijumpai dalam jumlah yang tidak terlalu tinggi. Hal ini disebabkan Ni memiliki tingkat kelarutan yang terbatas (limited solubility) yang menyebabkan unsur $\mathrm{Ni}$ akan terbawa oleh air tanah ke zona yang lebih dalam dan sebagian kecil tertahan di zona limonit. Unsur Ni pada zona limonit biasanya dijumpai dalam mineral gotit dan Mn oksida (asbolit) [10].

Dasar klasifikasi zona limonit berdasarkan unsur kimia adalah klasifikasi Golightly [11] yaitu: Fe (> 25 $\%), \mathrm{MgO}(<5 \%)$, dan $\mathrm{Ni}(<1,5 \%)$. Pada daerah penelitian kadar Fe pada zona limonit bervariasi dari $12 \%-$ $53 \%$. Mineral utama pada zona limonit yaitu gotit, mineral lempung (clay) seperti kaolin, magnetit, kromitsilika, kuarsa, hematit,dan juga tersusun sedikit serpentin [12]. Ketebalan zona limonit bervariasi dari $1-5$ meter.

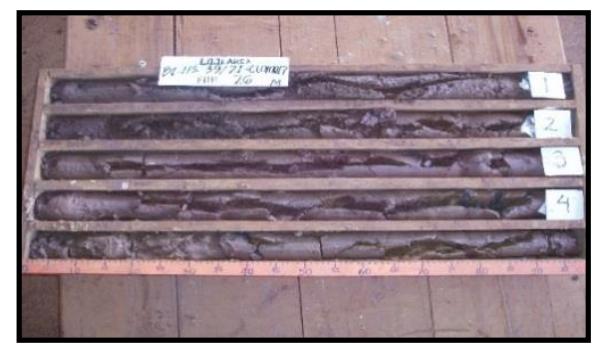

\section{b) Zona Saprolit}

Gambar 12. Inti Bor Zona Limonit

Pada zona saprolit dijumpai urat-urat antara lain garnerit, kuarsa, dan chrysopras. Zona saprolit kaya akan unsur-unsur $\mathrm{Ni}$, Co, dan $\mathrm{Cr}$, serta dijumpai fragmen-fragmen kuarsa. Secara kimiawi zona saprolit ditandai dengan kelimpahan unsur $\mathrm{Mg}$ dan $\mathrm{Ni}$ serta berkurangnya unsur Fe [13]. Hal tersebut disebabkan $\mathrm{Mg}$ dan $\mathrm{Ni}$ biasanya terakumulasi dalam mineral hydrous silika yang berasal dari leaching mineral primer penyusun batuan ultramafik [14]. Unsur Ni pada zona saprolit biasanya berasosiasi dengan mineral olivin, serpentin dan mineral hydrous silika seperti garnierit dan krisopras. Unsur yang bersifat immobile seperti Fe biasanya berkurang pada zona ini karena Fe biasanya terakumulasi sebagai residual enrichment pada zona limonit.

Dasar klasifikasi zona saprolit berdasarkan unsur kimia adalah klasifikasi Golightly (1979) yaitu: Fe $(<25$ $\%), \mathrm{MgO}(>5 \%)$, dan $\mathrm{Ni}(>1,5 \%)$. Seperti halnya pada zona limonit klasifikasi ini tidak dapat diterapkan sepenuhnya dalam pembagian zonasi menurut unsur kimia karena banyak dijumpai anomali di lapangan sehingga diperlukan sedikit penyesuaian. Hal ini disebabkan tiap daerah memiliki karakteristik yang khas namun tidak menyimpang terlalu jauh dari model umumnya.

Dari hasil deskripsi lapangan berdasarkan titik bor, zona saprolit dicirikan oleh kenampakan fisik dengan ciri khas warna coklat kekuningan, coklat kehijauan dan kuning kehijauan, ukuran butir pasir halus samapi kerakal. Juga dijumpai adanya fraksi material yang lebih kasar yang merupakan hasil pelapukan yang belum sempurna seperti bongkah batuan dasar, biasanya dijumpai mineral seperti serpentin, talk, olivin, garnierit, krisopras dan mineral-mineral hidrous silika lainnya. Pada umumnya saprolit pada daerah penelitian merupakan rock saprolit yaitu zona saprolit yang kaya akan fragmen batuan dasar yang masih tersisa. Ketebalan zona saprolit mencapai 16 meter.

(2019) 25-33 | http://ejournal.unkhair.ac.id/index.php/josae | ISSN 2621-3435 | 


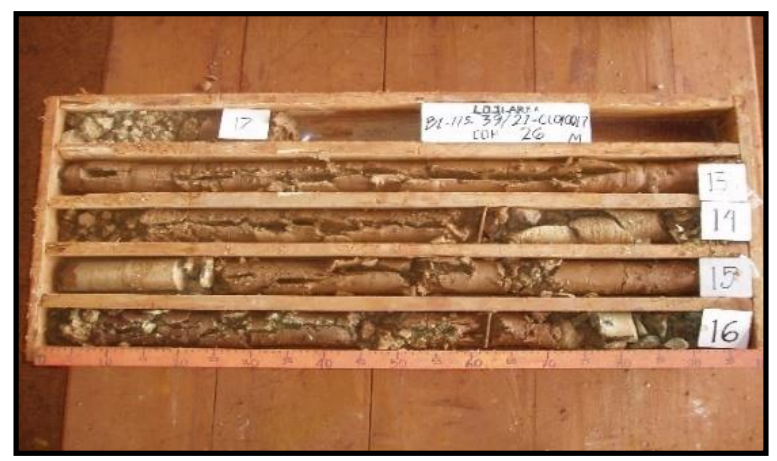

Gambar 12. Inti Bor Zona Saprolit

\section{c) Zona Bedrock}

Secara kimiawi zona bedrock merupakan zona yang memiliki komposisi kimiawi yang masih sama dengan batuan dasar yang masih fresh. Batuan dasar dari endapan nikel laterit pada daerah penelitian adalah di dominasi oleh dunit. Batuan tersebut umumnya mengalami serpentinisasi dengan intensitas lemah sampai tinggi (lihat lampiran deskripsi petrografi). Unsur yang umum dijumpai dalam konsentrasi yang tinggi adalah $\mathrm{Mg}$, sedangkan unsur $\mathrm{Ni}$ dan Fe semakin menurun konsentrasinya. Mineral yang umum dijumpai adalah mineral primer penyusun batuan tersebut yaitu olivin, piroksen dan serpentin, dan mineral tambahan kromit dan magnetit. Secara megaskopis zona bedrock dicirikan oleh batuan yang masih segar dengan tingkat pelapukan maupun serpentinisasi yang rendah, kompak, dan masif, masih memperlihatkan struktur, tekstur, dan komposisi asli dari batuan tersebu. Ciri khas warna hitam kelabu dan hitam kehijauan, kedalama bedrock mencapai $\pm 25 \mathrm{~m}$.

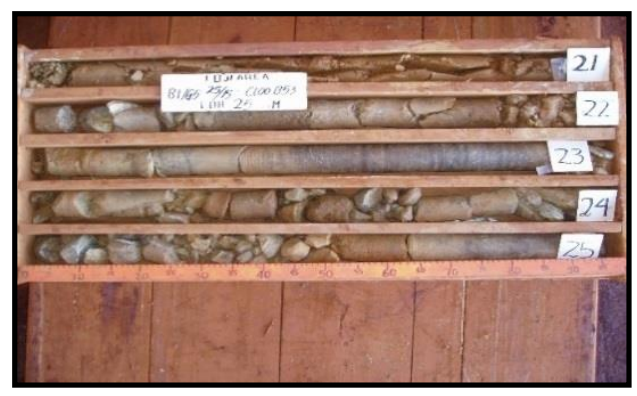

\subsection{KESIMPULAN}

Gambar 13. Inti Bor Pada Zona Bedrock

Berdasarkan hasil penelitian maka dapat disimpulkan sebagai berikut:

1. Penyebaran batuan yang terdapat di daerah penelitian pada umumnya dunit yang mengalami serpentinisasi dan menpunyai intensitas yang berbeda-beda, hal ini dapat terlihat dengan adanya rekahan pada bidang kristal yang terisi oleh mineral-mineral bidang kristal olivin dan piroksesn yang terisi oleh mineral serpentin.

2. Dari hasil olahan data profil geokimia di daerah penelitian menujukan bahwa terjadi ketidak normalan distribusi unsur-unsur yang ada, baik unsur $\mathrm{Ni}, \mathrm{Co}, \mathrm{Fe}, \mathrm{SiO}_{2}, \mathrm{CaO}$ dan $\mathrm{MgO}$. Hal ini dapat dipengaruhi faktor-faktor geologi seperti morfologi, topografi, struktur kekar serta rekahan-rekahan batuan ultrabasa yang mempunyai intensitas yang berbeda sehingga dapat dipengaruhi terhadap pengkayaan unsur-unsur yang berbeda pula, seperti terlihat pada profil geokimia setiap titik bor.

3. Berdasarkan penampang dari tiap-tiap zonasi menunjukan bahwa ketebalan dan kedalaman endapan nikel laterit dapat bervariasi.

\section{Ucapan Terima Kasih}

Ucapan terima kasih untuk person atau organisasi yang menjadi sponsor dari penelitian atau membantu penelitian. 


\section{Daftar Pustaka}

[1] Burger, P.A. Origins and Characteristic of Lateric Nickel Deposits, Nickel Seminar Proceedings, Kalgoorlie. p 179-183. 1996

[2] Edward, R., Atkisno, K. Ore Deposit Geology and Its Influence On Mineral Explorasion. 466. 1986

[3] Elias, M. Nickel Laterit Deposits - Geological Overview, Resource and Exploitatoin, Spesial Publication 4, Mick Elias Associates, CSA Australia Pty ltd, 24 p. 2003.

[4] Grant, J.A., 1986, The Isocon Diagram; a Simple Solution to Gresens' Equation for Metasomatic Alteration: Economic Geology, v. 81, p. 76-82. 1986

[5] Hamilton, 1978. Struktur Geologi Pulao Obi. Direktorat Geologi dan Sumberdaya Mineral Bandung.

[6] Tim Geologis PT Antam Tbk. Litologi Daerah Loji. Tidak dipublikasikan. 2001

[7] Sudana dkk. Lembar Geologi Pulau Obi. Direktorat Geologi dan Sumberdaya Mineral Bandung. 1994

[8] Idrus, A. Petrology, Geochemistry and Compositional Changesof Diagnostic Hydrothermal Minerals within the Batu Hijau Porphyry Copper-Gold Deposit, Sumbawa Island, Indonesia,Genehmigte Dissertation. 385 p. 2005.

[9] MacLean, W.H. Mass Change Calculations in Altered Rock Series: Mineralium Deposita, v. 25, p. 4449. 1990.

[10] Rose, A. W., Hawkes, H. E., and Webb, J. S. Geochemistry in Mineral Exploration, $2^{\text {nd }}$ Edition Academic Press, London. 657 p. 1979

[11] Golightly, J.P. Geology of Soroako Nickeliferous Laterite Deposite, Int. Laterite Simp, New Orleans. 1979

[12] Setiawan. Analisis Geokimia dan Unsur-Unsur Logam Serta Kadar Pada Endapan Nikel Laterit Pulau Obi. Tidak dipublikasikan. 2005.

[13] Ollier, C. Weathering, T. and A. Constable ltd, Great Britain, 304 p. 1969.

[14] Prijono, A. Potensial of the Lateritic-Nickel Deposits In Indonesia and Their Succesfull Development Much Depens on the Right Processing Method. OnThe Indonesian Mining Industry-It's Present and Future, The Indonesian Mining Association, Jakarta 184-250 p. 1977. 